\title{
PARA ALÉM DA FIXAÇÃO DOS CONTEÚDOS: UMA PROPOSTA DE HISTORICIDADE COMO ESTRATÉGIA DE TRANSPOSIÇÃO DIDÁTICA NO ESTUDO DA FÍSICA E NA FORMAÇÃO DOCENTE NA LICENCIATURA EM CIÊNCIAS BIOLÓGICAS
}

\author{
Maria Auxiliadora Delgado Machado \\ Carmen Irene Correia de Oliveira \\ Guaracira GouvêA de Sousa \\ Universidade Federal do Estado do Rio de Janeiro \\ (UNIRIO), Rio de Janeiro, Brasil
}

\begin{abstract}
Resumo: Nesse trabalho problematizamos as dificuldades dos alunos de um curso de licenciatura em Ciências Biológicas em transpor didaticamente conceitos relativos à queda dos corpos, observadas durante as aulas de regência em turmas de nono ano do Ensino Fundamental e discutimos uma estratégia de enfrentamento de tais dificuldades a partir da historicidade desses conceitos. Tal estratégia cumpriu um duplo objetivo tanto no que se refere à compreensão dos conteúdos por parte dos licenciandos na disciplina de física do curso, bem como na reflexão sobre suas práticas docentes já no estágio supervisionado. A partir de respostas e representações em forma de desenhos de conceitos sobre a queda dos corpos percebemos a necessidade de uma explicação pautada nas ideias desenvolvidas por Aristóteles, Buridan e Galileu. O contato com o processo de produção do conhecimento científico em diferentes épocas da história da ciência além de desconstruir erros antigos na formação dos licenciandos, fornece uma nova ferramenta pedagógica a ser incorporada em suas práticas docentes.

Palavras-chave: Ensino de ciências. Formação de professores. Transposição didática.
\end{abstract}


INTRODUÇÃO

Desde o ano de 2010, e conforme a Lei n 11.274/06, o segmento do Ensino Fundamental da Educação Básica no Brasil foi ampliado para nove anos, consistindo em duas etapas que passaram a ser tratadas como anos iniciais (primeiros cinco anos) e anos finais (últimos quatro anos). Para atuar nos primeiros anos, ainda segundo a referida lei, os educadores precisam ter formação mínima correspondente ao Ensino Médio completo, em sua modalidade profissionalizante de Formação de Professores ou nível superior em pedagogia. Geralmente, o educador deste segmento de ensino fica responsável pelo ensino de todas ou quase todas as disciplinas regulares, o que não ocorre no segundo segmento.

Para lecionar nos demais anos, correspondentes à segunda etapa do Ensino Fundamental, o educador precisa ter formação superior na área em que vai atuar, de maneira que cada educador atue na disciplina correspondente à sua formação universitária. No caso da disciplina Ensino de Ciências, obrigatória nesse segmento, os professores que atuam do sexto ao nono ano, em sua maioria, são egressos de licenciaturas em Ciências Biológicas (MILARÉ; PINHO-ALVES, 2010). No entanto, a grade curricular do Ensino de Ciências do nono ano geralmente é constituída por conteúdos de Física e Química, divididos em dois semestres e apresentados de forma muito segmentada, o que se constitui em um desafio para os professores em ação e também para a formação de professores.

Vale ressaltar que em diversos municípios do estado do Rio de Janeiro, a formação em Ciências Biológicas é uma condição necessária para participar de concursos para vagas de professores de ciências na esfera pública. Nesse sentido, ressaltamos também que os cursos de Licenciatura em Ciências Biológicas nas universidades públicas em diferentes regiões do estado oferecem disciplinas, tanto de física como de química, para o Ensino de Ciências. Essas disciplinas buscam problematizar os conteúdos específicos dessas ciências na forma de práticas pedagógicas para as aulas do nono ano do Ensino Fundamental, visando diminuir o estranhamento e desconforto desses futuros professores no que se refere aos conteúdos de astronomia, física e química; nem sempre plenamente contemplados em sua formação como os conteúdos de biologia.

Historicamente as licenciaturas em Ciências Biológicas se estruturaram seguindo um esquema $3+1$, dentro de uma racionalidade técnica, na qual os conteúdos específicos são oferecidos nos três primeiros anos do curso, e 
somente no quarto ano os alunos cumprem as horas exigidas para estágio, que atualmente, segundo a Lei no 11.788 de 2008, somam 420 h. Sendo assim, o estágio é dividido em duas etapas nomeadas por Estágios Supervisionados I e II, desenvolvidos nas aulas de ciências dos anos finais do Ensino Fundamental e nas aulas de biologia do Ensino Médio, respectivamente.

Por cerca de quatro anos a supervisão do Estágio Supervisionado I da licenciatura em Ciências Biológicas de nossa universidade foi feita pela professora da disciplina de Ensino de Física para o Ensino de Ciência, que logo de início observou que os licenciandos buscavam preferencialmente atuar nos anos escolares marcados por conteúdos somente de biologia, no caso sétimo e oitavo anos. Quando por algum motivo, em geral pela incompatibilidade de horários, os licenciandos precisavam atuar no nono ano, as notas das aulas de regência dadas pelos professores da escola eram sistematicamente menores que as notas daqueles que estagiavam em outros anos escolares. As maiores críticas vinham da dificuldade dos licenciandos em lidarem com alguns conceitos de física e química, optando por transformar a aula de regência em pequenos seminários e falar às turmas como se estivessem falando para os seus pares na universidade, evidenciando o total desconhecimento sobre o fluxo de conhecimento entre o saber científico e o saber ensinado, que foi materializado por Yves Chevalard (1998) na teoria de transposição didática. Esta constatação revelou também que o desconhecimento em como transpor didaticamente os conteúdos, em especial os de física, resulta de dificuldades dos próprios licenciandos, em cujo processo formativo aqueles conteúdos foram apresentados a partir de algoritmos matemáticos para solução de problemas, em detrimento de discussões sobre a natureza física dos conceitos e fenômenos.

Diante desse cenário iniciamos uma pesquisa que busca problematizar as dificuldades conceituais dos licenciandos de Ciências Biológicas nos conteúdos de física com um duplo objetivo: i) rever a transposição didática dos conteúdos trabalhados nas aulas de física enquanto componente curricular da licenciatura e possibilitar uma melhor compreensão dos conceitos envolvidos; e ii) introduzir a transposição didática como uma ferramenta pedagógica em suas futuras práticas docentes.

Como interface desse duplo objetivo, utilizamos o conceito de transposição didática na perspectiva de Chevallard (1998) que se apoia na diferença entre o saber produzido pelos cientistas (saber sábio) e o saber que circula nas salas de aula (saber escolar), este último muitas vezes condicionado às políticas públicas que definem entre coisas os currículos, aos projetos políticos pedagógicos, e mesmo às condições socioculturais da comunidade escolar. 
Entretanto, o processo de transposição didática entre o saber sábio e o saber a ser ensinado, demanda de "vigilância epistemológica" (CHEVALLARD, 1998, p. 49), que consiste no cuidado necessário para se evitar distorções do conhecimento de referência. Com esse cuidado em mente, pensamos que uma excelente maneira de se transpor didaticamente os conteúdos da física é resgatar os contextos de produção de alguns conceitos a partir de sua historicidade e refazer o trajeto pelo qual o saber escolar se afasta desse conhecimento científico. Concluímos que dessa forma os licenciandos podem perceber melhor o nível de compreensão que eles possuem acerca dos conteúdos, sendo capazes de reconhecer possíveis equívocos e principalmente como eles se instalaram desde momentos remotos de sua formação no Ensino Médio, ou até mesmo no Ensino Fundamental. Como consequência, a partir da identificação de tais equívocos será mais fácil evitá-los em suas práticas como futuros docentes.

Este artigo consiste em um recorte no qual apresentamos uma sequência didática sobre a queda dos corpos, desenvolvida com os licenciandos da licenciatura em Ciências Biológicas de nossa universidade no âmbito da disciplina Física para o Ensino de Ciências. Essa sequência didática é composta de duas perguntas específicas cujas respostas, algumas em forma de desenhos representando a queda dos corpos, são apresentadas e discutidas.

Quanto à metodologia utilizada, queremos ressaltar que esta deverá se constituir de forma mais robusta a partir da abordagem e análise de outras sequencias didáticas relativas a outros conteúdos. No momento atual, quando da elaboração deste artigo, nossa proposta não é apresentar formulações metodológicas legitimadas, mas, sobretudo mostrar o processo de desenvolvimento das explicações sobre queda dos corpos por parte dos licenciandos.

Para o desenvolvimento deste trabalho, apresentamos uma breve discussão sobre a relação entre história das ciências e ensino de ciências a partir do modo como ela funciona em nossas concepções. Em seguida apresentamos as análises das respostas obtidas e a consequente discussão que levou os alunos a uma melhor compreensão da teoria e das próprias dificuldades que apresentavam.

HISTÓRIA DAS CIÊNCIAS E ENSINO DE CIÊNCIAS

Em muitas discussões envolvendo ensino de ciências, algumas atreladas à cultura científica, parecem vir à tona a questão dos processos 
como fundamental para se situar os produtos científicos. A abordagem dos processos implica na historicidade de vários fatores e atores que estão envolvidos no desenvolvimento de uma teoria, de um conceito e dos produtos em ciência e tecnologia. Conforme nos relata El-Hani (2006, p. 3, grifo do autor), a literatura já aponta a relevância da história e filosofia das ciências para uma educação científica de qualidade, perspectiva que está na base das denominadas abordagens contextuais do ensino de ciências "nas quais se propõe que a aprendizagem da ciência deve ser acompanhada por uma aprendizagem sobre as ciências (ou sobre a natureza da ciência)".

Inicialmente, podemos afirmar que para haver história da ciência, deve haver uma área de conhecimento como objeto, que possui sua epistemologia e instrumentos próprios, e com as diferentes formas de abordagem. Acrescenta-se a esse fato que "a história tem a ver com atividades humanas, de preferência com as atividades socialmente relevantes", mas também dizem respeito a outros elementos que não são reduzidos à individualidade humana, como fenômenos legais, relações etc. (KRAGH, 2001, p. 24-25). Assim, a história da ciência tem como marca o segundo termo da expressão, a ciência percebida como um tipo de atividade humana única.

A relação entre a história da ciência e o ensino de ciências está presente em diferentes estudos e discussões de profissionais no campo da educação científica, sempre com destaque ao papel que a primeira pode ter em uma perspectiva mais bem-sucedida na disseminação do conhecimento científico.

No âmbito da cultura científica é perceptível que a discussão, arregimentando outras noções como as de alfabetização científica e divulgação científica, gira em torno de uma educação em ciências que forme cidadãos críticos tendo em vista a relação entre ciência, tecnologia e sociedade, o que não pode ser pensado excluindo-se uma abordagem contextual sobre o desenvolvimento científico. Ainda conforme El-Hani (2006), apesar do papel da ciência em nossa sociedade, os currículos de ciências ainda retratam uma prática científica separada da sociedade, da cultura e da vida cotidiana, o que parece se refletir na formação de professores na área.

A abordagem de conteúdos no campo da física, química e biologia carece de uma perspectiva que traga os modos como conceitos e teorias se desenvolveram a partir de um processo de trocas informacionais entre cientistas e pensadores e de uma relação com aparatos técnicos, pois usualmente apresenta um panorama no qual os fatos científicos são oriundos de descobertas de homens geniais e onde as teorias e fórmulas que as representam não têm nenhuma relação com fatos concretos e empíricos. 
Tendo em vista a nossa problemática, de modo mais específico, vemos que as concepções "erradas" relacionadas à mecânica em física já são estudadas em trabalhos que, no entanto, apresentam propostas de "correção" nas quais estaria ausente a perspectiva da historicidade. Tomemos, como exemplo, dois estudos interessantes com propostas diferenciadas. No primeiro, um estudo português intitulado"Física para todos: concepções erradas em mecânica e estratégias computacionais", onde Fiolhais e Trindade (1998) identificam a dificuldade dos alunos na aprendizagem em Física e a existência de um raciocínio baseado na física aristotélica e sugerem a adoção do computador com programas de simulação e jogos que trabalhariam o conceito de força e movimento para resolução desse problema. Nesse contexto, a ênfase estaria na questão do conceito correto a partir da teoria newtoniana.

No segundo, cujo título é"Modos de raciocínio baseados na teoria do impetus: um estudo com estudantes e professores do ensino fundamental e médio", Cunha e Caldas (2001) discutem os resultados de um estudo de caso onde foi aplicado um instrumento que identifica a existência de um modo de raciocínio baseado na teoria do impetus em estudantes do ensino fundamental e médio, mas, também, em professores desses níveis, indicando que "este modo de raciocínio é resistente, persistindo e convivendo, aparentemente sem muito conflito, com o conhecimento de ordem científica" (CUNHA; CALDAS, 2001, p. 99). Além de detectar, o estudo propõe que a adoção do instrumento, que traz respostas e posicionamentos dos alunos frente a questões que envolvem o movimento dos corpos, viabiliza uma melhor compreensão do uso das expressões e conceitos em sala de aula, o que podemos inferir pela recomendação dada aos professores: "evitar, a todo o custo, que a força exercida pelo objeto e a força do objeto se fundam numa única e mesma causa do movimento" (CUNHA; CALDAS, 2001, p. 102).

Os posicionamentos acima nos levam a pensar no uso do argumento da autoridade para ensinar aos alunos a concepção correta, aliado a estratégias que garantem, usualmente, a fixação do conhecimento. Diferentemente, pensamos que a adoção de uma explicação na qual as questões são contextualizadas do ponto de vista histórico se apresenta como estratégia que coaduna a percepção crítica e leva o aluno a pensar o como e o porquê dos processos.

De acordo com Martins (2006), a história das ciências pode auxiliar tanto em uma visão coerente acerca da natureza da ciência quanto no aprendizado dos conteúdos científicos, ressaltando que a história das ciências não é um substituto do ensino de ciências. Ele afirma que tanto professores quanto pesquisadores da área de ensino de ciências já perceberam que os 
alunos apresentam um conjunto de concepções prévias, anteriores ao ensino científico sistemático, que não podem ser ignoradas. Nesse sentido, mais do que apresentar a teoria correta com base no argumento de autoridade, é necessário conduzir o aluno a refletir criticamente sobre o modo como pensava anteriormente, que não se ajustava aos posicionamentos modernos. Por isso, de acordo com o autor, no lugar de ignorar tais concepções, é necessário trabalhá-las: reconhecê-las e gradativamente transformá-las para que elas não continuem a existir paralelamente às científicas.

Pensamos que para que ocorra uma transformação no modo de trabalhar as questões e não somente apresentar a teoria correta como modo de suplantar o raciocínio já enraizado, devemos nos apoiar no potencial da inclusão da história das ciências, com foco nos modos de construção do conhecimento e contextualização das questões científicas.

O enfrentamento dessa questão deve passar pelo conhecimento da história da ciência que pode ser útil à transformação conceitual, pois ela faculta ao aluno, além da aprendizagem da ciência, a aprendizagem sobre a ciência. $O$ "sobre" constitui o âmago do processo e envolve não somente a metodologia, mas, também, o contexto histórico. Tal enraizamento traz ao aluno uma ideia mais consistente acerca dos processos, pois elas emergem como elaborações humanas sistematizadas e historicamente contextualizadas. O "sobre" não nos é dado pelo desenvolvimento teórico, unicamente; nem pelo argumento de autoridade. Ele emerge na própria percepção do aluno que vê as fraturas do seu conhecimento.

A defesa da história das ciências no ensino de ciências tem, em sua base, diferentes justificativas que estão, de certo modo, relacionadas à cultura científica de modo mais amplo. Dentre tais justificativas, destaca-se a percepção da necessidade de levar o aluno a compreender o processo de desenvolvimento de um conceito ou teoria, desmitificando o fazer científico como obra de gênios, mas, ao mesmo tempo, situando tal obra no contexto de uma época e de uma corrente de pensamento. "O estudo histórico de como um cientista realmente desenvolveu sua pesquisa ensina mais sobre o real processo científico do que qualquer manual de metodologia científica" (MARTINS, 2006, p. XIX).

Desse modo, pensar na cultura científica de modo mais amplo é situar o desenvolvimento científico para além de datas, nomes e memorização de conceitos. Ganha destaque, também, a perspectiva gradual e coletiva de construção do conhecimento científico e o fato de que a ciência não é resultado imediato, linear e imediato da aplicação de um método científico 
que permite alcançar uma verdade. Tais percepções têm de um modo ou de outro, dificultado a mudança do imaginário social relativo ao fazer científico, e tal imaginário impregna aqueles que chegam aos bancos escolares em todos os níveis. Como nos traz Delizoicov (2006), o discurso do professor e os livros constituem o meio fundamental, no espaço escolar, de disseminação do conhecimento científico.

No entanto, os livros que são adotados na educação científica são construídos para deixar o estudante familiarizado com os conceitos de uma determinada área, realizando simplificações que excluem do ensino da ciência outros fatores que estão implicados no desenvolvimento científico, como as diferentes experimentações, os fracassos, os sucessos, o trabalho colaborativo entre cientistas com base em trocas informacionais, enfim, as disputas e controvérsias. Isso contribui para uma perspectiva de ciência neutra, até mesmo desumanizada, no sentido de que os cientistas são personagens, mais do que seres humanos com incertezas acerca dos rumos de seus desenvolvimentos ou envolvidos em disputas.

Uma perspectiva que parece estar sempre presente nas proposições dos autores trabalhados é que o potencial da história da ciência no ensino de ciência reside, dentre outros fatores, na possibilidade de oferecer ao aluno o modo de raciocínio que impulsionou a discussão sobre alguns conceitos por diferentes teóricos em diferentes épocas, facilitando a transposição didática desses mesmos conceitos para o saber ensinado. Desse modo, o aluno pode vislumbrar o fazer científico e não somente seus produtos teóricos e/ou materiais, pois ele poderia contextualizar os fatos e compreender as implicações sociais, políticas e ideológicas presentes em cada época.

\section{O PROCEDIMENTO DIDÁTICO EM FOCO: O NOSSO CAMPO}

Para Menga Lüdke e Marli André (1986), os objetivos pretendidos com a análise de dados são estabelecidos pelo quadro teórico da pesquisa, mas é possível que algumas hipóteses a serem investigadas surjam ao longo da análise. O fato de não existirem hipóteses ou questões específicas formuladas a priori não implica a inexistência de um quadro teórico que oriente a coleta e a análise de dado. O desenvolvimento do estudo assemelha-se a um funil: no início há uma questão ou focos de interesse muito amplos, que no final se tornam mais diretos e específicos. O pesquisador vai visualizando melhor esse foco à medida que o estudo se desenvolve. 
A imagem do funil trazida pelas autoras é bastante útil para descrever as ações desenvolvidas pela professora da universidade e que constituem o recorte apresentado nesse trabalho. Tais ações se estruturaram a partir de um viés exploratório no sentido trazido por Triviños (1987). Segundo esse autor, uma pesquisa com estas características costuma ser realizada quando se objetiva uma formulação mais precisa de problemas ou hipóteses a partir do esclarecimento de conceitos e ideias com a intenção não somente de modificá-los, mas também visando o desenvolvimento de procedimentos mais sistematizados que poderão se converter nas bases para pesquisas semelhantes.

Sendo assim, esse trabalho surge a partir de duas constatações quase simultâneas de que os licenciandos em Ciências Biológicas mostravam muita dificuldade em planejar e ministrar de forma satisfatória suas aulas de regência com conteúdos de física durante os estágios nas escolas, bem como evidenciavam um entendimento equivocado sobre esses conteúdos. Focalizando a queda dos corpos, observamos que os equívocos sobre queda livre eram advindos da necessidade em se conhecer a massa dos corpos para resolver os problemas, enquanto sobre o movimento oblíquo, a confusão, em geral, estava relacionada ao desconhecimento do valor da força inicial que colocou o projétil em movimento. Essas observações vêm sendo feitas, a cada semestre, desde o semestre inicial de 2012, o que equivale a um mínimo de dezesseis turmas nos últimos quatro anos, onde cada turma era composta aproximadamente por quinze a vinte alunos, totalizando cerca de 150 alunos. A seguir elencamos as principais etapas da pesquisa pensadas no sentido de se estabelecer uma estratégia de trabalho.

$\checkmark \quad$ Relação dos licenciandos com a disciplina de física

No primeiro semestre de 2012, ficou claro, já na primeira aula, que a maior parte da turma além de não gostar de física, o que de certa forma é comum entre os licenciandos em Ciências Biológicas, não via nenhum motivo para estudar essa disciplina no seu processo de formação em biologia, mesmo na licenciatura. Tal postura se traduzia em representações construídas ao longo da educação básica, com uma provável culminância no ensino médio período quando, em função das provas de acesso à universidade, a física é apresentada de forma extremamente algoritimizada, tornando sua manipulação em uma tarefa difícil e sofrida.

Em face dessa nova componente a professora iniciou um processo de reflexão sobre como dar significado a física para esses licenciandos. 
A mera cotidianização de alguns conceitos como inércia, ação gravitacional, atrito, ou outros tantos, não seria suficiente para vencer a barreira de rejeição dos alunos.

$\checkmark \quad$ Ressignificando a física

A professora elegeu um significado que provavelmente não fora trabalhado pelos licenciandos de Ciências Biológicas em sua experiência acadêmica até então: a contribuição da física para a construção de uma visão de mundo e como tal construção se apoiava em paradigmas que podiam ser quebrados e substituídos por outros, refletindo, nessa dinâmica, o saber construído em uma época e a repercussão desse saber com a sociedade daquele momento. A partir dessa intenção, iniciou-se o processo de afunilamento citado anteriormente, onde a professora elege como campo exploratório o campo da história da ciência para mostrar esse caminho trilhado em meio à construção de conhecimento necessária a uma visão de mundo. Além disso, essa perspectiva poderia atuar como um elemento para humanizar a física frente aos alunos.

\section{$\checkmark \quad$ Planejamento das atividades didáticas}

As atividades foram planejadas de forma a serem realizadas no início do semestre, mais especificamente em duas aulas (cada uma com duração de quatro horas) onde alguns conceitos básicos, familiar aos alunos nos conteúdos do Ensino Médio, foram problematizados na perspectiva da história da Ciência, conforme descrevemos a seguir.

Aula 01

- Primeira atividade: A fim de se estabelecer um contato amigável com os licenciandos foi solicitada uma pesquisa sobre as contribuições de Aristóteles para a biologia. As pesquisas efetuadas seguem uma tendência muito comum a esse tipo de atividade atualmente, o famoso "recorta e cola" de algum material na internet. Mesmo assim, durante a discussão realizada é evidente a surpresa para muitos licenciandos sobre o trabalho de catalogação e classificação que Aristóteles desenvolveu com algumas espécies de plantas e principalmente com mais de cem espécies de peixes, tendo sido considerado por esse fato o precursor da ictiologia. Dessa forma foi evidenciada a componente histórica na construção dos conhecimentos de biologia, em geral desconhecida em seu processo formativo. 
- Segunda atividade: Levantamento dos conhecimentos de cada aluno sobre os aspectos relativos à queda dos corpos e ao lançamento oblíquo. Imediatamente após a discussão sobre a relação de Aristóteles com a biologia, em um clima em geral mais ameno e descontraído, os alunos são solicitados a responder em uma folha avulsa que deverá ser entregue a professora os seguintes exercícios:

1. Imagine dois corpos esféricos, idênticos na forma, constituídos de materiais diferentes e consequentemente com diferentes massas, lançados ao solo da mesma distância. Considerando o tempo para chegar ao solo, compare os tempos de cada um.

2. Imagine um corpo sendo lançado de forma oblíqua. Desenhe as grandezas físicas atuando sobre esse corpo.

A representação por imagens de algumas explicações científicas envolve concepções de ciência e, também, de analogia entre o que se quer explicar (uma abstração, por exemplo) e sua esquematização por meio de desenhos: ou seja, entre a ideia e a imagem que a representa. $O$ modo como percebemos a função de uma imagem em ciência é importante para situar as questões que vamos problematizar no entrecruzamento das explicações científicas e suas trajetórias históricas. Nesse sentido, é importante deixar claro que consideramos os desenhos elaborados pelos alunos um documento que indicia o grau de compreensão da teoria que eles procuram representar. Ou seja, tais desenhos constituem o modo como eles externalizam o entendimento que têm da queda dos corpos.

As respostas à questão 1 e os desenhos solicitados na questão 2, evidenciam as dificuldades observadas em relação aos conteúdos sobre a queda dos corpos. Na sequência de desenhos mostrados na Figura 1 podemos constatar claramente essa dificuldade.

No Quadro 1, listamos o quantitativo de respostas corretas e incorretas obtidas nesses últimos quatro anos. Podemos observar que a cada semestre cerca de $50 \%$ a $70 \%$ das respostas dos alunos indicam que os corpos com maior massa caem antes daqueles com menor massa e que um número ainda maior equivocadamente entende que a força inicial no momento do lançamento oblíquo de um corpo não só é responsável pelo seu movimento, como também se mantém no corpo durante todo o seu percurso. 
Figura 1: Sequência de desenhos produzidos pelos licenciandos

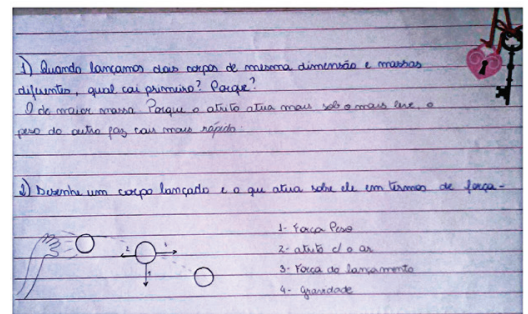

(a)

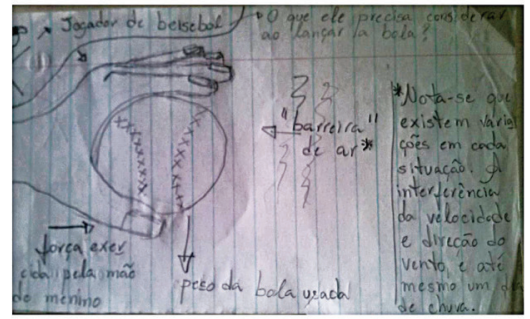

(c)

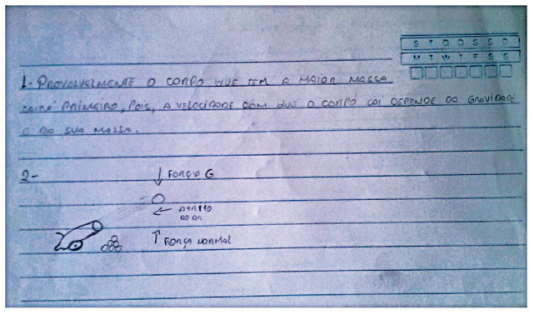

(b)

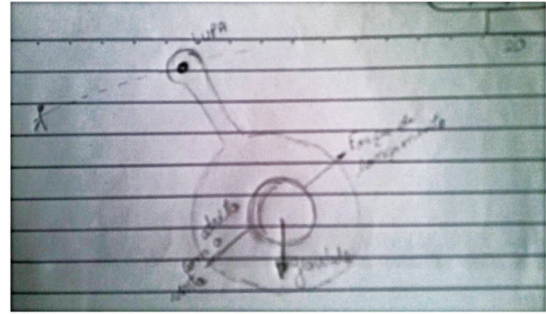

(d)

Quadro 1: Quantidade de respostas certas e erradas por turma, por semestre

\begin{tabular}{|c|c|c|c|c|c|}
\hline \multirow{2}{*}{$\begin{array}{l}\text { Turmas por } \\
\text { semestre letivo }\end{array}$} & \multirow{2}{*}{$\begin{array}{l}\text { Total de alunos } \\
\text { por turma }\end{array}$} & \multicolumn{2}{|c|}{ Questão 1} & \multicolumn{2}{|c|}{ Questão 2} \\
\hline & & Acerto & Erro & Acerto & Erro \\
\hline 2012.1 & 12 & 2 & 10 & 1 & 11 \\
\hline 2012.2 & 17 & 8 & 9 & 5 & 12 \\
\hline 2013.1 & 23 & 5 & 18 & 2 & 21 \\
\hline 2013.2 & 17 & 2 & 15 & 0 & 17 \\
\hline 2014.1 & 13 & 1 & 12 & 0 & 13 \\
\hline 2014.2 & 21 & 6 & 15 & 4 & 17 \\
\hline 2015.1 & 22 & 6 & 16 & 4 & 18 \\
\hline 2015.2 & 25 & 5 & 20 & 1 & 24 \\
\hline
\end{tabular}

Fonte: elaboração própria

Aula 02:

- $\quad$ Primeira atividade: Dedução da função horária da posição para o movimento uniformemente variado (MUV). Para isso os alunos, organizados em duplas ou trios, são levados a deduzir a equação $x-x_{0}=v_{0} t+(a t) / 2$ para o MUV a partir de uma sequência de 
algoritmo ditada pela professora. Em seguida, de posse dessa equação, velha conhecida desde o ensino médio, os alunos devem calcular o tempo de queda de dois corpos de massas $m_{1}$ e $m_{2}$ $\left(m_{1}>m_{2}\right)$, lançados de certa altura. $O$ único esforço é expressar a equação em termos da coordenada vertical y para constatar que a massa não entra nos cálculos. Esse momento em geral traz muita surpresa para muitos alunos que se perguntam por que isso não fora compreendido antes, quando eles estavam no Ensino Médio.

- Segunda atividade: $O$ exercício anterior é ampliado a fim de se analisar um lançamento oblíquo, notadamente bidimensional em relação ao plano cartesiano xy. Dessa forma é feita uma combinação entre a função horária de posição para a componente horizontal do movimento (eixo $x$ ) e analogamente a função horária para a componente vertical do movimento (eixoy). Os alunos não têm dificuldade em compreender que a componente do deslocamento ao longo do eixo x será constante e dependerá única e exclusivamente da intensidade da velocidade inicial e do ângulo de lançamento e ambos definirão o alcance do objeto. Por outro lado, o movimento ao longo do eixo y é o mesmo da queda livre unidimensional, estando o corpo somente sob ação da aceleração da gravidade.

Nesse momento são trabalhados dois textos com o intuito de problematizarmos historicamente alguns aspectos do movimento dos corpos. No primeiro texto, Dias, Santos e Souza (2004) apresentam as ideias de Aristóteles para a queda dos corpos, enfatizando como ele relacionava a rapidez (no sentido de velocidade) com a massa e a resistência (conceito bastante nebuloso em Aristóteles) do corpo contra o movimento. Dessa forma, os corpos com maiores massas teriam mais condições de romper a resistência natural e chegar mais rapidamente ao solo do que aqueles com massas menores.

No segundo texto, Caldas e Cunha (2001) descrevem a teoria de Buridan para o movimento de corpos lançados obliquamente que consistia em considerar que todo o corpo teria uma qualidade permanente a qual ele denominou de Impetus, que não desapareceria com a separação entre o corpo e o agente responsável pela ação motora, embora pudesse ser destruída por agentes contrários tal como a resistência do ar ou pela tendência contrária do corpo. Os alunos identificam nessa teoria as suas próprias ideias, que implicam em trabalhar erroneamente o conceito de força, ao raciocinar que essa segue impressa em um corpo mesmo quando não há contato. 
Finalmente as folhas avulsas que haviam sido recolhidas pela professora, contendo as respostas às questões colocadas na primeira aula são devolvidas aos alunos que avaliam e percebem os equívocos cometidos tanto no que diz respeito à massa dos corpos, bem como à atuação da força em um lançamento oblíquo de um corpo em movimento uniformemente acelerado.

Esse é um momento muito importante para o estabelecimento de uma relação entre a professora e os alunos, pois tem o propósito de romper com os obstáculos impostos pela física escolar permitindo uma reflexão por parte dos alunos que apontam os principais pontos que emergiram na aula, e que pode ser sistematizado em dois conjuntos de conclusões, um referente ao conteúdo de física trabalhado e outro relativo à metodologia de usar a história da ciência em sala de aula.

1. Sobre os conteúdos de física:

- A massa não entra nos cálculos da queda dos corpos.

- A força é uma grandeza de contato e não fica "presa" a um corpo após o lançamento

2. Sobre a abordagem pela história da ciência:

- A surpresa ao se darem conta de que pensam como Aristóteles e Buridan.

- Como um pensamento, que se apresenta lógico diante do que é observado, pode ser inadequado e explicado de forma surpreendente em outro período histórico, rompendo com as ideias anteriores e servindo para o avanço da construção de novos conhecimentos ao longo da história da humanidade.

Os desdobramentos dessa atividade têm sido incorporados às aulas no sentido de promover a discussão de quais seriam, na opinião dos licenciandos as questões e temas dos conteúdos de Ensino de Ciências que poderiam ser trabalhados com auxílio das ferramentas pedagógicas das disciplinas da educação de forma a possibilitar uma formação mais ampla e mais humanizada.

\section{CONSIDERAÇÕES FINAIS}

Nesse artigo, apresentamos os primeiros resultados de uma pesquisa que busca introduzir a historicidade de conceitos e fenômenos da física como possibilidade de transposição didática tanto na aprendizagem por parte dos licenciandos em Ciências Biológicas na disciplina de Física para o Ensino de 
Ciências, bem como na sua atuação como estagiários em turmas do nono ano do Ensino Fundamental. Adotamos a perspectiva de Chevallard (1991) que entende a transposição didática como a transformação do saber científico em um saber ensinado, que circula na sala de aula.

No presente recorte, descrevemos o desenvolvimento de uma sequência didática relativa ao conteúdo movimento dos corpos que, a partir da história das ciências, busca retomar o contesto de produção de alguns conceitos e processos, a fim de mostrar como o saber científico produzido nesses contextos se encontra deslocado do saber ensinado em sala de aula. Durante oito semestres são demandadas duas atividades, uma relacionada à queda livre e outra ao lançamento oblíquo.

A partir de um levantamento das respostas corretas e incorretas constatamos que, independente do quantitativo das respostas, a lógica de Aristóteles de concepção de massa e a lógica de Bouridan para o conceito de Impetus está internalizada em muitos futuros professores de ciências, em pleno século XXI. Mais do que um problema, tal internalização funciona como um obstáculo epistemológico, que, na perspectiva de Gaston Bachelard, limita a compreensão de outras questões e a ampliação da visão de mundo. Se isso ainda ocorre com esses licenciandos, é muito provável que tal limitação seja estendida aos seus futuros alunos. Essa limitação de visão de mundo influencia não somente o processo formativo, mas principalmente apropriação do mundo em que vivemos e das construções de conhecimentos que nele permeiam. Pretendemos no futuro, incorporar as ideias de obstáculo epistemológico e de perfil epistemológico dos conceitos tanto no processo formativo dos licenciandos, como em suas práticas de estágio, para que eles iniciem um processo de reflexão sobre as consequências de uma inadequação na compreensão dos conteúdos nos diversos campos do conhecimento.

Diante do que foi exposto neste artigo, a proposta de apresentar a trajetória histórica dos conceitos relacionados ao movimento dos corpos, tomando como pontos de partida a mecânica de Aristóteles e a Teoria do Impetus, de Buridan, por conta de suas respostas e dos desenhos elaborados, proporcionou um deslocamento dos alunos de modo a refletir sobre a sua própria representação do fenômeno. Tal percepção emergiu naturalmente nas aulas, dispensando artifícios de autoridade que privam os alunos de um exercício de criticicidade. Perceber que a genialidade dessas pessoas tem sua origem em dúvidas acerca de ideias simples ainda presentes em nossa forma de ver o mundo, humaniza a ciência tornando-a mais palatável 
e mesmo desejável. Nesse aspecto, o ensino de ciências numa perspectiva da história das ciências pode contribuir para uma educação que se pretende transformadora e libertária.

\section{BEYOND THE MEMORIZATION OF CONTENTS: A PROPOSAL OF HISTORICITY AS DIDACTIC TRANSPOSITION STRATEGY IN THE STUDY OF PHYSICS AND TEACHER TRAINING IN THE UNDERGRADUATE COURSE IN BIOLOGICAL SCIENCES}

AвSTRACT: In this work, we problematize the difficulties faced by students in a licentiate course in Biological Sciences in teaching concepts related to the fall of bodies, observed during conducting classes in Basic Education $9^{\text {th }}$ year groups. We also discuss a strategy to deal with these difficulties through the historicity of these concepts. This strategy has served a dual purpose either regarding the understanding of the contents of the undergraduate discipline or in reflection on their teaching practices in supervised training. From answers and representations, we realized the need for an explanation based on the ideals developed by Aristotle, Buridan and Galileo. The contact with the production process of scientific knowledge in different periods of history of science allowed students to, beyond deconstructing old mistakes in teacher education, incorporate a new pedagogical tool on their teaching practices.

KEYWORDS: Science teaching. Teacher formation. Didactical Transposition.

MÁS ALLÁ DE LA FIJACIÓN DE LOS CONTENIDOS: UNA PROPUESTA DE LA HISTORICIDAD COMO ESTRATEGIA DE TRANSPOSICIÓN DIDÁCTICA EN EL ESTUDIO DE LA FÍSICA Y DE LA FORMACIÓN DOCENTE EN EL GRADO EN CIENCIAS BIOLÓGICAS

RESUMEN: En este trabajo discutimos las dificultades que tienen los alumnos de un curso de formación de profesores en Ciencias Biológicas para ultrapasar didácticamente conceptos relacionados a la caída de los cuerpos, observadas durante las clases de prácticas docentes en clases para alumnos del noveno año de la enseñanza básica y discutimos una estrategia de confronto para esas dificultades, partiendo de la historicidad de esos conceptos. Esta estrategia ha servido a un propósito dual, tanto en lo que se refiere a la comprensión de los contenidos por parte de los estudiantes universitarios en el curso de la asignatura física, así como para reflexionar sobre sus 
prácticas de enseñanza ya en el entrenamiento supervisado. A partir de las respuestas y representaciones mediante dibujos de los conceptos sobre la caída de los cuerpos nos dimos cuenta de la necesidad de una explicación pautada en las ideas de Aristóteles, Buridan y Galileo. El contacto con el proceso de producción del conocimiento científico en diferentes períodos de la historia de las ciencias, además de desconstruir viejos errores en la formación del pregrado, proporciona una nueva herramienta pedagógica a ser incorporada a sus prácticas docentes.

Palabras Clave: Enseñanza de ciencias. Formación de Profesores. Transposición didáctica.

\section{REFERÊNCIAS}

BRASIL. Lei no 11.274, de 6 de fevereiro de 2006. Disponível em: <http://www.planalto.gov.br/ccivil_03/_ato2004-2006/2006/lei/I11274.htm>. Acesso em: 21 set. 2016.

BRASIL. Lei no 11.788, de 25 de setembro de 2008. Disponível em: <https://www. planalto.gov.br/ccivil_03/_ato2007-2010/2008/lei/l11788.htm>. Acesso em: 21 set. 2016.

CUNHA, A. L.; CALDAS, H. Modos de raciocínio baseados na Teoria do Impetus: um estudo com estudantes e professores do Ensino Fundamental e Médio. Revista Brasileira de Ensino de Física, Florianópolis, n. 23, p. 93-103, jan./mar. 2001.

CHEVALLARD, Y. La Transposición Didáctica: del saber sabio al saber enseñado. Buenos Aires: Aique, 1998.

DELIZOICOV, N. C. Ensino do Sistema Sangüíneo Humano: a dimensão histórica-epistemológica. In: SILVA, C. C. (Org.). Estudos de História e Filosofia das Ciências: subsídios para aplicação no Ensino. São Paulo: Editora Livraria da Física, 2006. p. 265-286.

DIAS, P. M. C.; SANTOS, W. S.; SOUZA, M. T. M. A Gravitação Universal (Um texto para o Ensino Médio), Revista Brasileira de Ensino de Física, n. 26, p. 257-271, jul./set. 2004.

EL-HANI, C. N. Notas sobre o ensino de história e filosofia das ciências na educação científica de nível superior. In: SILVA, C. C. (Org.). História e Filosofia da Ciência no Ensino de Ciências: da Teoria à Sala de Aula. São Paulo: Editora Livraria da Física, 2006. p. 3-21.

FIOLHAIS, C.; TRINDADE, J. A. Física para todos: concepções erradas em mecânica e estratégias computacionais. In: SILVA, P. A. (Org.). A Física no Ensino na Arte e na Engenharia, Instituto Politécnico de Tomar, Tomar, 195-202, 1999. Disponível em: <http:// nautilus.fis.uc.pt/personal/jtrindade/ jtrindade/pub/24.pdf>. Acesso em: 22 maio 2016. 
KRAGH, H. Ideologia e mitos na História da Ciência. In: KRAGH, H. Introdução à Historiografia da Ciência. Porto: Porto Editora, 2001. p. 119-165.

LUDKE, M.; ANDRÉ, M. E. D. A. Pesquisa em Educação: abordagens qualitativas. São Paulo, Editora Pedagógica e Universitária, 1986.

MARTINS, R. A. Introdução: a história das ciências e seus usos na educação. In: SILVA, C. C. (Org.). Estudos de História e Filosofia das Ciências: subsídios para aplicação no ensino. São Paulo, Editora Livraria da Física, 2006. p. XVII-XXX.

MILARÉ, T.; PINHO-ALVES, J. Ciências no nono ano do ensino fundamental: da disciplinaridade à alfabetização científica e tecnológica. Ensaio: Pesquisa em Educação em Ciências, v. 12, p. 101-120, 2010.

TRIVIÑOS, A. N. S. Introdução à pesquisa em ciências sociais: a pesquisa qualitativa em educação. São Paulo, Editora Atlas, 1987.

Maria Auxilladora Delgado Machado: Doutora em Astronomia pelo Observatório Nacional. Atualmente é professora do Programa de Pós-Graduação em Educação, na Universidade Federal do Estado do Rio de Janeiro (UNIRIO) e professora adjunta no Departamento de Ciências da mesma universidade, onde desenvolve pesquisa em formação inicial e continuada de professores de ciências a partir de parcerias com escolas públicas de ensino fundamental e médio. Trabalha também com a relação ciência e artes na dinâmica de ensino-aprendizagem de ciências.

E-mail: dora.dm@gmail.com

Carmen Irene Correia de Oliveira: Doutora em Ciência da Informação pela Universidade Federal Fluminense (UFF). Atualmente é professora adjunta do Departamento de Ciências Sociais da Universidade Federal do Estado do Rio de Janeiro (UNIRIO), sendo docente no Programa de Pós-Graduação em Educação da mesma Universidade. Desenvolve pesquisas no âmbito da educação, nas temáticas de educação/cultura/ divulgação científica; educação científica, imagens fixas e em movimento; memória e imagem, com discussões ancoradas nas relações entre ciência, tecnologia e sociedade.

E-mail: irenecor2004@gmail.com 
GuaraciRA GouvêA dE SousA: Doutora em Educação, Gestão e Difusão em Biociências pela Universidade Federal do Rio de Janeiro (UFRJ). Atualmente, é professora associada da Universidade Federal do Estado do Rio de Janeiro (UNIRIO), e docente permanente do Programa de Pós-Graduação em Educação desta instituição. Tem experiência na área de Educação, com ênfase em educação não formal, mídias e educação à distância, atuando principalmente nos seguintes temas: educação em ciências, linguagens/imagens, museu de ciências e formação de professores nas modalidades presencial $e$ à distância.

E-mail: suaraciras@uol.com.br 
